\title{
The 3M National Teaching Fellowship: Findings from a National Questionnaire on the Impact of the Program
}

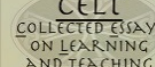

2017 CELT VolX

celt.uwindsor.ca www.stlhe.ca

STLHE SAPES

Arshad Ahmad, McMaster University

Denise Stockley, Queen's University

Ron Smith, Concordia University

Amber Hastings Truelove, Queen's University

DOI: 10.22329/celt.v10i0.4744

In 2016 the $3 M$ National Teaching Fellowship reached a milestone in celebrating the $30^{\text {th }}$ anniversary of the first fellowship in 1986. The fellowship is the premier award of the Society for Teaching and Learning in Higher Education and each year up to 10 fellows are announced. Thus far, there has not been a systematic review or evaluation of the fellowship program. This study is a starting point to engage the various stakeholders and gather their perspectives regarding the fellowship program. This paper highlights the findings of a national questionnaire that targeted 3M National Teaching Fellows, administrators, educational developers, faculty, and students. The findings provide a snapshot of the awareness of the fellowship, the impact of fellows on their institutions and beyond, and recommendations for the future of the program.

$\mathrm{T}$ he 3M National Teaching Fellowship (3MNTF) is seen by many as Canada's most prestigious recognition of excellence in university teaching and educational leadership. In fact, $42 \%$ of the administrators, faculty, educational developers (EDs), and students who responded to the survey were aware of the Fellowship, compared to $18 \%$ who were aware of other national teaching awards. Since 1985, 3M Canada and the Society for Teaching and Learning in Higher Education (STLHE) have recognized $3083 \mathrm{MNTFs}$, from more than 80 Canadian Universities representing almost all of the disciplines in the Academy. This paper is part of a three-year study that explores the overall impact of the 3MNTF. The study began in 2012 at the 3MNTF Retreat in Banff with focus group interviews of $3 \mathrm{M}$ senior administrators, 3M Fellows, 3M retreat facilitators, EDs, and program coordinators. A detailed account of the focus group findings has been accepted in Innovations in Education and Teaching International. In the second phase of this study, and the focus of this paper, we developed a questionnaire which was sent to 3M Fellows, faculty, administrators, students and members of the STLHE community at several Canadian universities to assess various aspects about the Fellowship program including awareness, influence, process related questions, and overall impact. 


\section{Rationale for the Study}

In the 30 years since the first $3 \mathrm{MNTF}$ was awarded, many people have been involved in the program; not only those who have won the award, but also faculty who have been nominated, EDs who helped mentor nominees and assembled nomination packages, administrators who have nominated colleagues, and students who have been taught by $3 \mathrm{M}$ award winners. Despite the potential for the award to have a far-reaching impact, this study is the first attempt to define that impact on diverse members of the academic population. As the $3 \mathrm{MNTF}$ award program enters its next 30 years, we have an opportunity to define how the award program, and its Fellows, have impacted their institutions, and the impact that Fellowship has had on successful nominees. For the purposes of our study, we defined impact in terms of the effect that the $3 \mathrm{MNTF}$ has had on individual winners, the influence that fellows have been able to exert within their institutions after being awarded the 3MNTF, and the national and international influence of the 3MNTF award program. For members of the teaching and learning community who are currently developing their teaching portfolios in anticipation of a $3 \mathrm{M}$ nomination, recognizing the diverse impacts of the award could be very beneficial.

Teaching awards that recognize teaching excellence in higher education have existed for a number of years, and there have been numerous attempts to define the impact that they have had on the landscape of higher education (Aron et al. 2000; Brawer et al, 2006; Frame, Johnson, \& Rosie, 2006; Olsson \& Roxå, 2008; Skelton, 2004). Sorcinelli and Davis (1996) reported that the University of California awarded its first institutional teaching award in 1959, while the University of Massachusetts, Amherst launched a similar program in 1962. At the departmental and institutional levels teaching awards can be a way to publicly acknowledge outstanding teachers. Nancy Van Note Chism (2006) found that teaching awards were instituted for three main reasons: "Institutions hope to symbolically acknowledge their support for teaching, to recognize the accomplishments of excellent teachers, and to encourage other faculty to achieve similar levels of performance in teaching." National awards schemes, like the Canadian 3M Fellowship, the National Teaching Fellowship Scheme of the Higher Education Funding Council for England, and The Australian Awards for University Teaching use teaching awards to officially provide recognition for teachers who demonstrate excellence and who often go beyond their discipline and institution. Halse et al. (2007) argue that "unofficially, the awards seek to counter the privileged position of research by improving the importance and status of teaching in universities" (p. 731). The desire to recognize and encourage higher levels of teaching excellence may explain why countries are increasingly instituting national teaching awards programs. The 3MNTF's holistic approach to teaching awards, by demanding evidence not only of teaching excellence, but also of leadership in teaching, has been used internationally by countries seeking to set up their own national teaching awards programs (Leibowitz, Farme, \& Franklin, 2012; Alexander \& O'Mahony, 2015). South Africa started the National Teaching Excellence Awards in 2009, and The National Academy for the Integration of Research and Teaching and Learning (NAIRTL) Excellence in Teaching Awards scheme existed in Ireland from 2007 to 2012. Both of these awards programs were modelled after Canadian programs and the $3 \mathrm{MNTF}$ program in particular (Leibowitz et al., 2012; Alexander \& O’Mahony, 2015).

\section{Methodology}

In March of 2016, we sent out a survey to administrators, faculty, EDs, and students at Canadian Universities to determine their perceptions of the impacts of the $3 \mathrm{M}$ National Fellowship program and $3 \mathrm{M}$ Fellows. This survey was approved by research ethics boards at McMaster University and Queen's University. We received 1084 responses to this survey; however, not all participants responded to each question. In a gateway question on the first page of the survey, we asked respondents "are you aware of the 3M National Teaching Fellowship (3MNTF)?” If 
they answered no to this question, then the survey was terminated. This eliminated 515 surveys. There were also a number of respondents who did not continue the survey beyond the first question. In total, 379 participants provided useable responses for the entire questionnaire. Although we collected demographic information from all of the respondents, only those who were aware of the Fellowship were included in the data analysis.

\section{Results}

When asked to identify their primary academic discipline, $21 \%$ of the 1084 respondents from the full dataset indicated that they primarily identify with the Health Sciences, 20\% with the Social Sciences, 20\% with the Natural Sciences, 9\% with Engineering, $13 \%$ with the Humanities, and 6\% with Business. Of the respondents, $8 \%$ identified with other disciplines, including Education and Law. While the student category provided the largest number of terminated responses for the gateway question, it was surprising to see that $31 \%$ of administrators, $22 \%$ of faculty, and $9 \%$ of EDs were also unaware of the Fellowship. Respondents self-identified across a range of positions (administrator, faculty, ED, student) and disciplines from institutions across Canada.

To determine the impacts of the $3 \mathrm{MNTF}$ on individual segments of our survey population, we applied branching within FluidSurvey as a way to ask specific questions of different demographic groups. We asked respondents "what role do you most identify with (choose one even if multiple roles apply)?" Based on the participants who were aware of the Fellowship, almost half (47\%) identified themselves as faculty, while $32 \%$ identified themselves as students, $8 \%$ as EDs, and $8 \%$ as administrators. There was a range of responses from the $6 \%$ who identified as other, including researcher, staff, graduate student, and alumni. Student responses were excluded from questions related to the institutional impact of the award, and questions directed to faculty.

Looking at all responses to the survey, we found that a correlation analysis identified a weak, positive relationship between the number of years a person has spent in higher education, and their awareness of the $3 \mathrm{M}$ Fellowship; $r(\mathrm{~N}-2)=0.30$, $\mathrm{p}<0.001$. This is encouraging since it suggests that as individuals progress in their careers, and become more aware of the award, they can begin engaging in leadership in teaching activities that can place them in a position to be nominated for a $3 \mathrm{MNTF}$.

The $3 \mathrm{MNTF}$ is regarded by many faculty, staff, students, and administrators as the best known and most prestigious teaching recognition/awards program in Canada. Slightly fewer than half (42\%) of all survey respondents were aware of the $3 \mathrm{MNTF}$. Students were the most likely to respond that they were not aware of the fellowship (77\%), while almost all EDs were aware of it (91\%) (Table 1). Only 18\% of all respondents answered yes when asked: "are you aware of other national teaching and learning awards?" Examples provided by those who were aware of other awards included the Alan Blizzard Award, the Knapper Award, and the College Sector Educator Award. Many respondents also included the $3 \mathrm{M}$ National Student Fellowship on this list, and while this is not a teaching award, it may speak to the close association that has been forged between $3 \mathrm{M}$ and the teaching fellowship.

We also asked respondents whether "teaching awards at your institution have been influenced by the $3 \mathrm{M}$ National Teaching Fellowships." 236 respondents (faculty, administrators, and EDs) provided answers. Of these, $25 \%$ responded yes, $13 \%$ responded no, while the majority, $61 \%$, were unsure. For those who answered yes, we provided a text response box asking for additional details. Of the 56 people who elaborated on this question, eight suggested that the $3 \mathrm{M}$ has helped to raise the visibility of teaching excellence at their institutions. For one respondent, the importance of the $3 \mathrm{MNTF}$ as an award has also helped to draw attention to other, more localized teaching awards:
Absolutely! There appears to be a growing sense of the importance of recognizing teaching excellence at the schoolldept, institutional, regional, and national levels. In that regard, there are initiatives to encourage 
Table 1

Awareness of $3 M N T F$ cross-tabulated by role

\begin{tabular}{lccccc}
\hline Role & \multicolumn{5}{c}{ Awareness of 3M Fellowship } \\
\cline { 2 - 5 } & Yes & No & Yes $\%$ & No \% & Total Responses \\
\hline Administrator & 29 & 13 & $69 \%$ & $31 \%$ & 42 \\
Educational Developer & 31 & 3 & $91 \%$ & $9 \%$ & 34 \\
Faculty & 177 & 51 & $78 \%$ & $23 \%$ & 228 \\
Student & 121 & 407 & $22 \%$ & $77 \%$ & 528 \\
Other & 21 & 41 & $34 \%$ & $66 \%$ & 62 \\
Total number of respondents & 379 & 515 & & & 894 \\
Total percentage of respondents & $42 \%$ & $58 \%$ & & & $100 \%$ \\
\hline
\end{tabular}

nominations for such awards at each level and where possible through these progressive stages.

Ten respondents indicated that their institutions have brought their local awards in line with the requirements for the $3 \mathrm{MNTF}$. One respondent pointed out that "we have recently aligned our Institution-wide awards to the $3 \mathrm{M}$ process," while another noted that "we designed an educational leadership award to parallel the leadership half of the 3M." Six respondents pointed out that the alignment between university awards and the 3MNTF can help to identify and prepare future $3 \mathrm{M}$ nominees. That the structure of the 3MNTF has helped to shape local and regional teaching awards is indicative of its importance as a national award.

\section{Nomination Process}

The majority of EDs, faculty, and administrators $(82 \%)$ are aware of faculty at their institutions who have been nominated for a $3 \mathrm{MNTF}$. And while the 3MNTF call for nominations (STLHE www.STLHE.ca) provides clear and specific guidelines about what is expected in the dossier in terms of criteria to be included and the types of evidence that are expected, the responses to our survey suggest that there is some confusion among these groups about who initiates the nomination process.
Almost half, $30 \%$, are unsure who initiates the nomination process at their institutions (Table 2). Nine out of the 22 text responses to the "other" option indicated that the process involved selfnominations.

The primary aspect of the nomination process requires nominees to create a dossier that presents evidence of their teaching excellence and their leadership in education (Knapper \& Wright, 2001). Evidence of these qualities can take many forms. Ahmad, Stockley, and Moore (2013) provide the following examples for excellence in teaching and in leadership:

Examples of teaching excellence include the candidate's philosophy of teaching, the teaching strategies used to support the philosophy, teaching awards and recognition, student ratings, course development, letters of support and other related evidence. Examples of leadership evidence include the candidate's statement of what leadership in teaching excellence means and how it is accomplished; this is supported by actual contributions including workshops on teaching and learning, mentorship, research on teaching, and impact on educational development with the institution and beyond. (p. 184) 
Table 2

Knowledge of who initiates the nomination process cross-tabulated by role

\begin{tabular}{lcccc}
\hline & Administrator & $\begin{array}{c}\text { Educational } \\
\text { Developer }\end{array}$ & Faculty & Total Responses \\
\hline Administration & $8(27.6 \%)$ & $6(20.7 \%)$ & $15(51.7 \%)$ & 29 \\
Department Heads & $7(13.5 \%)$ & $9(17.3 \%)$ & $36(69.2 \%)$ & 52 \\
Deans & $7(22.6 \%)$ & $5(16.1 \%)$ & $19(61.3 \%)$ & 31 \\
Colleagues & $11(15.5 \%)$ & $11(15.5 \%)$ & $49(69.0 \%)$ & 71 \\
Centre for Teaching & $8(9.2 \%)$ & $19(21.8 \%)$ & $60(69.0 \%)$ & 87 \\
and Learning & $14(12.4 \%)$ & $11(9.7 \%)$ & $88(77.9 \%)$ & 113 \\
Unsure/Other & & & & \\
\hline
\end{tabular}

Putting together a dossier involves contributions from a variety of people. When asked if they have "participated in preparing a 3M National Teaching Fellowship nomination for yourself or others, $69 \%$ of administrators, students, faculty and EDs responded "no." Of the $31 \%$ who have participated in preparing a nomination, $25 \%$ wrote a reference, $12 \%$ assisted as the principal nominator, $11 \%$ provided administrative support, and $1 \%$ provided research support (Table 3). Of the $49 \%$ who responded "other" most seemed to use this option to identify the multiple roles in which they provided support. As one participant pointed out, "I was a nominee and prepared all the written portions; I was also a mentor for another nominee; and I have also written letters of support." Those nominated for a $3 \mathrm{MNTF}$ require the support of colleagues, students, administrators, and students to write letters of reference and to assist in assembling the nomination package. To be nominated for a $3 \mathrm{MNTF}$ is a group effort that goes

\section{Table 3}

Support for nominations provided by role

\begin{tabular}{lcccccc}
\hline & Administrator & $\begin{array}{c}\text { Educational } \\
\text { Developer }\end{array}$ & Faculty & Student & Other & $\begin{array}{c}\text { Total } \\
\text { Responses }\end{array}$ \\
\hline $\begin{array}{l}\text { Administrative } \\
\text { support }\end{array}$ & 4 & 5 & 4 & 0 & 0 & 13 \\
Principal nominator & 3 & $(38.5 \%)$ & $(30.8 \%)$ & $(0.0 \%)$ & $(0.0 \%)$ & \\
& $(20.8 \%)$ & 1 & 10 & 0 & 1 & 15 \\
& & $(6.7 \%)$ & $(66.7 \%)$ & $(0.0 \%)$ & $(6.7 \%)$ & \\
Reference writer & 2 & 1 & 17 & 5 & 3 & 28 \\
& $(7.1 \%)$ & $(3.6 \%)$ & $(60.7 \%)$ & $(17.9 \%)$ & $(10.7 \%)$ & \\
Research support & 0 & 0 & 0 & 1 & 0 & 1 \\
& $(0.0 \%)$ & $(0.0 \%)$ & $(0.0 \%)$ & $(100.0 \%)$ & $(0.0 \%)$ & \\
Other & 2 & 6 & 45 & 1 & 1 & 55 \\
& $(3.6 \%)$ & $(10.9 \%)$ & $(81.8 \%)$ & $(1.8 \%)$ & $(1.8 \%)$ & \\
\hline
\end{tabular}




\section{Table 4}

Relationship between role within a $3 M$ application, and the number of hours contributed to the application process

\begin{tabular}{lccccc}
\hline Hours & $\begin{array}{c}\text { Administrative } \\
\text { support }\end{array}$ & $\begin{array}{c}\text { Principal } \\
\text { nominator }\end{array}$ & $\begin{array}{c}\text { Reference } \\
\text { writer }\end{array}$ & Other & $\begin{array}{c}\text { Total } \\
\text { Responses }\end{array}$ \\
\hline $0-30$ & 8 & 8 & 22 & 24 & 62 \\
$31-60$ & 4 & 3 & 1 & 10 & 18 \\
$61-90$ & 0 & 1 & 0 & 2 & 3 \\
$91-300$ & 1 & 2 & 0 & 9 & 12 \\
\hline
\end{tabular}

well beyond the individual nominee.

Preparing a nomination package for the 3MNTF can be a daunting undertaking because of the time commitment involved. Those who have participated in producing a nomination package were asked, "approximately how many hours did you spend in preparing the nomination from start to finish?" The 95 respondents to this question had answers that ranged from one hour to 200 hours (Table 4). The vast discrepancy between the two extremes may reflect the particular role that a respondent played in the nomination process. Writing a letter of reference may only require a commitment of one or two hours, while coordinating the application process may require 30 or 40 hours. Nominees who must reflect on their teaching practices, articulate their teaching philosophy, and provide evidence for their teaching effectiveness and leadership may dedicate a large number of hours to the process.

\section{Impact}

The $3 \mathrm{MNTF}$ award program has the potential for a broad range of impacts on the individual award winners, their departmental colleagues, and their member institutions. These impacts, both positive and negative, are what make the $3 \mathrm{MNTF}$ unique among award programs.

\section{Influence on the Institution}

Questions that were specifically addressed to EDs, faculty, and administrators indicate that the majority of these respondents (82\%) knew that there were $3 \mathrm{MNTF}$ at their current institutions. Five percent of respondents did not know of any $3 \mathrm{MNTF}$ at their institutions, while $11 \%$ were unsure. While there is no direct evidence to suggest that knowledge of $3 \mathrm{M}$ Fellows at an institution is the same as Fellows having influence at their institutions, the large number of positive responses suggests that these Fellows are a visible part of their institutions.

The institutional impact of $3 \mathrm{MNTF}$ can be difficult to gauge, especially for those who may only be peripherally aware of the program. This may account for the 78 out of 223 respondents (35\%) who replied "unsure" when asked, "what impacts have $3 \mathrm{M}$ National Teaching Fellows had on your institution." Of the remaining respondents, $28 \%$ replied that $3 \mathrm{MNTF}$ have had a moderate impact on their institutions, $16 \%$ responded that they have had a small impact, $13 \%$ of respondents replied that they have had a large impact, while $6 \%$ said that they had no impact. When we isolated the responses from $3 \mathrm{M}$ Fellows, the no impact and small impact percentages remain similar, but a significant number of respondents indicated that fellows had a moderate to large impact on their institutions (Figure 1). How 


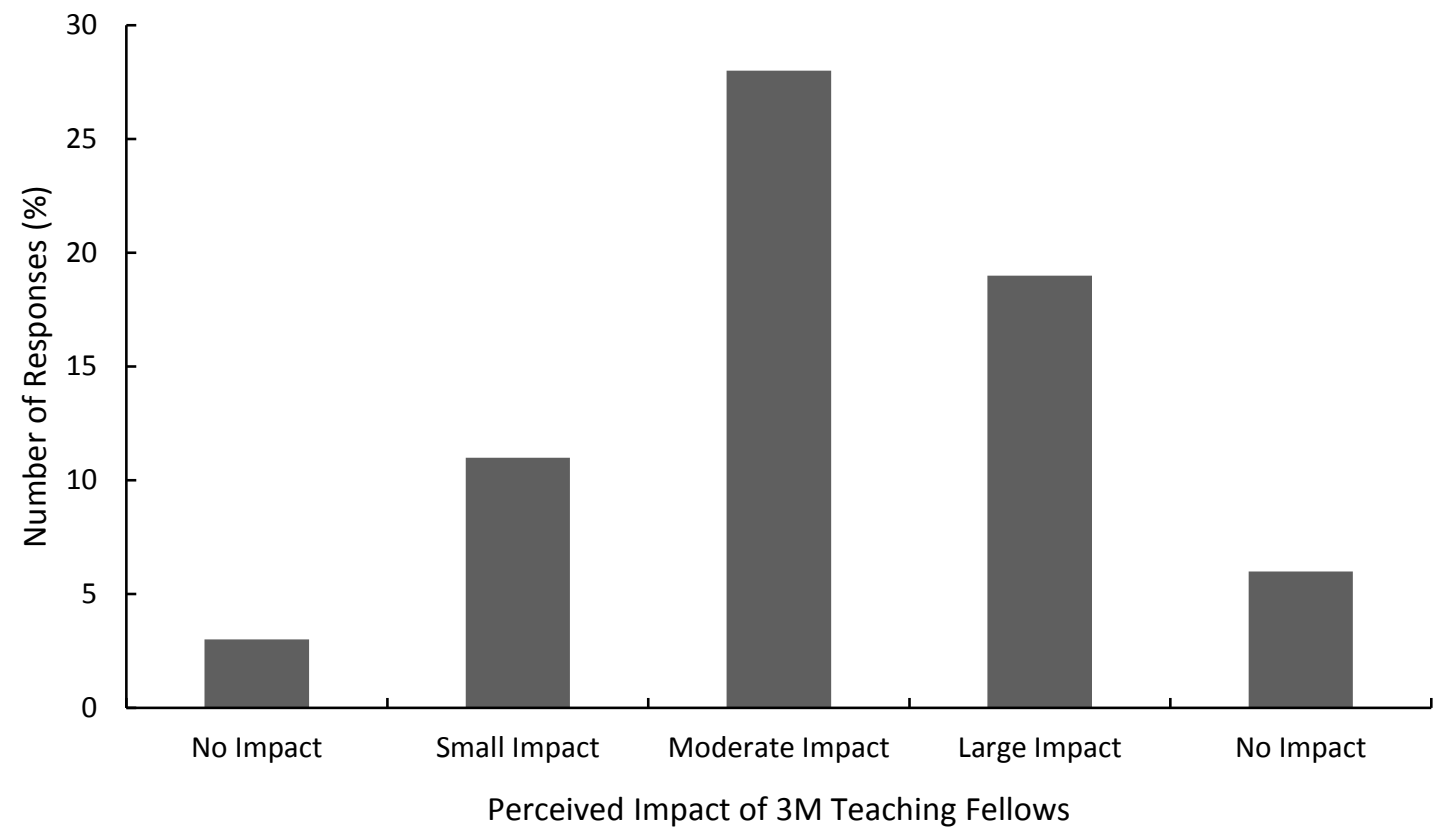

Figure 1

Percent of surveyed $3 \mathrm{M}$ Fellows indicating the degree of impact of the 3M Fellowship on their institution

respondents identified impacts became clearer when we asked them to elaborate on their answers. We provided a text box asking people to elaborate on this question, and of the 139 responses, 20 of them suggested that university teaching was impacted by having 3 MNTFs at their institution as these educators are involved in university initiatives around teaching and learning, mentoring other faculty members, and teaching students. Some respondents suggested that the impact of the award is largely dependent on the culture of the institution. In institutions where "research is still the primary driver of careers," Fellows may be perceived as having less impact. One Fellow suggested that "the impression many of us have is that they are used for optics, to make it look like our large research oriented institution cares about undergraduate teaching, despite contradictory evidence." Fellows are perceived as having the greatest impact in institutional cultures that celebrate and support teaching as a valuable contribution on par with research.

The survey also asked respondents to differentiate between the impact that $3 \mathrm{MNTF}$ winners have on their institution and the impact that the $3 \mathrm{MNTF}$ program has on their institutions. When asked "what impacts has the 3M National Teaching Fellowship Program had on your institution," many EDs, faculty, and administrators (42\%) replied that they were unsure. This is perhaps indicative of the difficulty in identifying differences between the impact of individual fellows, and the more general impact of the program. For those who noted a difference, many indicated that the program provides an opportunity to focus on the importance of teaching, and raises the bar in terms of what is considered to be excellence in teaching:

[It] has raised the stature of teaching on campus, by providing a Gold Standard. This has result[ed] in greater support and recognition of teaching at all levels. My analogy would be that whenever a Canadian wins a Gold Medal at the Olympics, that sport can expect a surge in grassroots participation and in official government funding.

Others suggested that the program acts as a "possible or conceivable milestone" which educators can "strive to achieve." It draws attention to "the aspects of teaching excellence to which we wish all teachers to aspire." For one respondent, the impact of the program is in its creation of teaching fellows: 
I don't see the program itself being a driving force for particular change. However, a $3 M$ Fellow does have doors open a little quicker for new initiatives and the promotion of change of practice. So I would say the program enables the $3 M$ Fellow. .."

Even institutions that do not currently have 3MNTFs can be impacted by the program through inviting $3 \mathrm{M}$ Fellows from other institutions to host workshops or provide talks.

\section{Influence on Centres for Teaching and Learning}

Individually, many Fellows contribute to the culture of teaching and learning at their home institutions by contributing to the teaching and learning centres on campus. The 28 EDs who completed the survey indicated an even split between fellows who contributed and those who did not. Only 6 (21\%) were unsure about $3 \mathrm{M}$ Fellows' contributions to their centres. From the $11 \mathrm{EDs}$ who provided qualitative clarification to their answers, we found that while some 3MNTFs are involved in "running workshops, and in teaching leadership positions," and receive "invitations to be on committees," one indicated that "participation with the centre seems unrelated to the award." One respondent suggested that it depends on what is meant by 'contribute', since $3 \mathrm{M}$ Fellows who have taken high-level administrative positions may be in a position to support teaching and learning initiatives in Centres for Teaching and Learning, and institutionally more broadly rather than working directly in Centres for Teaching and Learning.

\section{Influence on Faculty, Administrators, and EDs}

When asked to describe "the impact of successful 3M National Teaching Fellowship nominations at your institution," many faculty suggested that it raises awareness of teaching and learning. One respondent suggested that the

profiling of [a] winner raises awareness of
excellent leadership in teaching; $3 M$ award
winners have an influence on the teaching of
their departmental colleagues; winners are
profiled during University ceremonies
celebrating teaching and research
achievements.

Another suggested that successful nominations impact faculty in "the 'Professor of Teaching' track, and that successful $3 \mathrm{M}$ winners have a better chance at promotion in the traditional scholarly track, especially from Assistant to Associate Professor."

In contrast, faculty who have not won a 3 MNTF had mixed responses when asked to "describe the impact of unsuccessful 3M National Teaching Fellowship nominations at your institution." While many respondents suggested that they could not discern any institutional impact since this is essentially private information that unsuccessful nominees may choose not to disclose, one respondent suggested that for unsuccessful nominees, putting together the application package is "a huge time suck" which may take time away from other responsibilities. While the time dedicated to putting together an application package can be substantial, one respondent suggested that even unsuccessful nominations can be a boost for the department: "while we may experience initial disappointment there is always a spirit of celebration on having been nominated." Some respondents also suggested that despite the disappointment, the process of reflection involved in the submission process was beneficial, and often led to a future successful nomination. Whether being nominated but not winning is seen as a positive or a negative impact by nominees may be related to institutional culture. Individuals from institutions which value and celebrate nominees as well as winners may have more positive feelings about their nomination. The relationship between institutional culture and perceptions of unsuccessful nominations may be fruitful ground for future research. 


\section{Influence on Individual 3MNTF}

The $3 \mathrm{MNTF}$ is more than just a recognition of teaching excellence; rather it is the entryway to a national fellowship of individuals deeply committed to promoting excellence in higher education. Of the 225 faculty, administrators, and EDs who responded to this question, 70 were Fellows. The years in which they entered the Fellowship ranged from 1987 to 2015. When asked "how did receiving this award impact you professionally," most 3MNTFs felt that winning the award has had a positive impact on their professional lives. Confidence was a word that came up repeatedly in their comments; one Fellow said that it "gave me more confidence, opened doors, allowed my opinion and voice to resonate more," and another that

it gave me confidence to take the necessary risks associated with innovative teaching, and encouraged me to speak both at the institution and nationally about the importance of teaching and learning.

Some 3MNTFs also mentioned that becoming a Fellow assisted in their promotion to full professor. Others noted that it created new career opportunities for them, or validated their current career paths. Six of the Fellows noted that since winning the $3 \mathrm{M}$, there have been increased invitations to give talks, author textbooks, and generally become more involved in "higher level conversations" about teaching. Many $3 \mathrm{M}$ Fellows mentioned being called on to participate in more teaching and learning initiatives in their departments and institutionally. While many felt the Fellowship validated them as teachers, many also said that they valued being part of an "equally active and dedicated cohort" who can provide support and advice. For at least one 3MNTF, however, winning was a mixed blessing as he/she recalled experiencing "jealousy, back-biting, vicious personal attacks within the institution; a remarkable acceptance within the region and a wonderful reception within the STLHE itself." Overwhelmingly, becoming a 3M Fellow was described as an amazing experience which reinforced the value of teaching.

\section{Influence on Students}

Students in the classroom reap the benefits of having $3 \mathrm{MNTF}$ as instructors for their courses. These students recognize and appreciate the noticeable, although sometimes subtle, differences that $3 \mathrm{MNTF}$ bring to the classroom experience. For those who identified as students, and who indicated that they were aware of the $3 \mathrm{MNTF}, 38$ out of $101(37 \%)$ said that they had been taught by a $3 \mathrm{MNTF}, 24 \%$ said that they had not been taught by a $3 \mathrm{MNTF}$, while the majority, 39\%, said that they were unsure. When asked to provide additional details of their experiences, 33 students provided qualitative responses. Of those who had been taught by a 3MNTF, most detected a noticeable difference between 3MNTFs and their other teachers. Many students suggested that $3 \mathrm{MNTF}$ engage in more innovations in the classroom. They also suggested that $3 \mathrm{MNTF}$ are skilled at being able to explain complex ideas simply. One student said that

I have been taught by multiple professors who have won a 3M National Teaching Fellow. These instructors were enthusiastic about engaging their students, had a passion for the material, and took great lengths to teach in a manner that reflected their desire for students to really learn and develop.

Another student suggested that

There is a noticeable degree of difference in faculty members who have a $3 M$ background compared to those that don't. It would be inaccurate to say they are overall better lecturers (since I believe the quality of education stems from the lecturers' passion for the subject), as a student the experience was definitely more rich. The subtle details and overall fluidity of the course was apparent.

These differences are perhaps not surprising given that when asked "to describe any impacts of the 3M National Teaching Fellowship regarding your influence on student learning," many fellows suggested that they did not see any noticeable impact. Rather, they continued to do the things that allowed them to win the award in the first place. As one respondent pointed out, 
I got the award because I am a good teacher. I'd do that anyway, with or without the award. The award means that more people than just the students in my class know that I am a good teacher. However, I doubt that students care. I still have to be good in their particular classes.

For others, however, winning the award has increased their confidence, which they feel translates into being more effective in the classroom, or that they feel a greater responsibility to live up to the reward:

The validation of my teaching practice meant that I could go forward with greater confidence. What positive feedback regarding classroom results I have had is owing in part to the recognition that comes with a $3 M$ Fellowship.

[I] Feel more accountable to deliver really well-planned classes; mentor students more who are struggling; focus on social justice i.e., are students who are not in the social norm getting their needs met?

\section{Discussion}

While many of the respondents were not aware of the award (58\%) those who were aware of it, either as recipients, colleagues, EDs, students, or administrators, were often able to identify the various ways that the awards program, and its winners, impact the institutions of which they are part. Since the award recognizes outstanding teaching and leadership in teaching, winning a $3 \mathrm{MNTF}$ confers an additional authority on its recipients. This authority can be used by winners to have a greater say in the way that these issues are approached at their institutions. It can also allow them to be a resource for the institution and for their departments on matters related to teaching and learning.

One of the final questions we asked participants was "how can we increase the impact of the 3M National Teaching Fellowship?" What emerged most frequently was a desire to increase the visibility of the fellowship, and to make it as widely known as possible. Many people suggested highlighting the work that Fellows have been doing since receiving the award. Others point to the increased exposure that comes from the Fellowship's partnership with Maclean's magazine and suggest doing more to publicly acknowledge Fellows. Some suggestions include "op-eds that rebut the criticisms of governments, business and parents," and public lectures or workshops with Fellows, especially at institutions that may not currently have Fellows. One Fellow suggested that $3 \mathrm{M}$ Fellows "should be the public face of higher education in Canada."

It is not only faculty, EDs, and administrators who desire an increased public presence of 3M Fellows. A number of students said that they knew very little about the program, and would like to see more information about it distributed to the student population. While many Fellows are reluctant to tell students that they hold a Fellowship, the student responses to this question make it clear that they want to know about their professors' accomplishments.

This research provides an overview of the impacts of the $3 \mathrm{MNTF}$ in relation to the individual Fellows, their departments, and their institutions. More research is needed in terms of the potential impact of $3 \mathrm{M}$ Fellows in their communities and in their classrooms. A larger survey of the experiences of students who have been taught by Fellows would also be a productive direction for additional research.

\section{References}

Ahmad, A., Stockley, D., \& Moore, R. (2013). 3M Fellows making a mark in Canadian higher education. In D. J. Salter (Ed.), Cases on Quality Teaching Practices in Higher Education (pp. 182-190). Hershey, PA: IGI Global. VIEW ITEM

Aron, D. C., Aucott, J. N., \& Papp, K. K. (2000). Teaching awards and reduced departmental longevity: Kiss of death or kiss Goodbye. What happens to excellent clinical teachers in 
a research intensive medical school? Medical Education Online, 5(1), 4313. VIEW ITEM

Alexander, D. M., \& Mahony, C. O. (2015). Recognition, reward and impact: $A$ review of the national awards for excellence in teaching in higher education. Cork IE: National Academy for Integration of Research, Teaching and Learning. VIEW ITEM

Brawer, J., Steinert, Y., St-Cyr, J., Watters, K., \& Wood-Dauphinee, S. (2006). The significance and impact of a faculty teaching award: disparate perceptions of department chairs and award recipients. Medical Teacher, 28(7), 614-617. VIEW ITEM

Chism, N. V. N. (2006). Teaching awards: What do they award? The Journal of Higher Education, 77(4), 589-617. VIEW ITEM

Frame, P., Johnson, M., \& Rosie, A. (2006). Reward or award? Reflections on the initial experiences of winners of a National Teaching Fellowship. Innovations in Education and Teaching International, 43(4), 409-419. VIEW ITEM

Halse, C., Deane, E., Hobson, J., \& Jones, G. (2007). The research-teaching nexus: what do national teaching awards tell us? Studies in Higher Education, 32(6), 727-746. VIEW ITEM

Leibowitz, B., Farmer, J., \& Franklin, M. (2012). Teaching excellence awards in South Africa: A national study. In HE Monitor (No. 13). Pretoria, SA: The Council on Higher Education. VIEW ITEM

Knapper, C., \& Wright, W. A. (2001). Using portfolios to document good teaching: Premises, purposes, practices. New Directions for Teaching and Learning, 2001(88), 19-29. VIEW ITEM

Olsson, T., \& Roxå, T. (2008). Evaluating rewards for excellent teaching - a cultural approach. In Research and Development in Higher Education: The Place of Learning and Teaching Engaging Communities (Vol. 31, pp. 261-272). Rotorua, NZ: Higher Education Research and Development Society of Australasia, Inc. VIEW ITEM

Sorcinelli, M. D., \& Davis, B. G. (1996). Honoring exemplary teaching in research universities. New Directions for Teaching and Learning, 1996(65), 71-76. VIEW ITEM

Skelton, A. (2004). Understanding "teaching excellence" in higher education: a critical evaluation of the National Teaching Fellowships Scheme. Studies in Higher Education, 29(4), 451-468. VIEW ITEM

Warren, R., \& Plumb, E. (1999). Survey of distinguished teacher award schemes in higher education. Journal of Further and Higher Education, 23(2), 245-255. VIEW ITEM

\section{Acknowledgements}

Thanks to Brittany Harding for assisting with the data analysis. We would like to thank 3M Canada and the Society for Teaching and Learning in Higher Education for their ongoing support of this project.

\section{Biographies}

Dr Arshad Ahmad is the Associate Vice President, Teaching and Learning and the Director of MIIETL at McMaster University. He is the former President of the Society for Teaching and Learning in Higher Education.

Dr Denise Stockley is a Professor and Scholar in Higher Education with the Office of the Provost seconded to the Faculty of Health Sciences and crossappointed to the Faculty of Education at Queen's 
University. She is the President-Elect of the Society for Teaching and Learning in Higher Education.

Dr Ronald Smith is Professor Emeritus of Education at Concordia University and is Past Chair of the $3 \mathrm{M}$ Council of National Teaching Fellows. He directed the Centre for Teaching and Learning Services for 24 years.

Dr Amber Hastings-Truelove is a Post-Doctoral Fellow in educational development in the Faculty of Health Sciences. She has also worked as an educational development associate with Queen's Centre for Teaching and Learning. 